\title{
A 1000 YEAR GLACIOCHEMICAL STUDY AT THE SOUTH POLE
}

by

\author{
Severine Kirchner and Robert J. Delmas
}

(Laboratoire de Glaciologie et Géophysique de l'Environnement, B.P. 96, 38402 St Martin d'Hères Cédex, France)

\begin{abstract}
Major soluble chemical impurities have been measured along a $130 \mathrm{~m}$ firn core from the Amundsen-Scott Station in order to assess Southern Hemisphere environmental variability over the last millennium. Particular attention is given to the possible impact of the Little Ice Age, a well-known climatic disturbance which occurred in the Northern Hemisphere between about A.D. 1500 and 1900.

$\mathrm{Na}^{+}, \mathrm{K}^{+}, \mathrm{NH}_{4}^{+}, \mathrm{Cl}^{-}, \mathrm{SO}_{4}{ }^{2-}$ and $\mathrm{NO}_{3}^{-}$concentrations were carefully determined in forty-two $40 \mathrm{~cm}$ firn sections. Stringent precautions were taken to ensure the analytical reliability of the data set obtained. The average concentrations are (in $\mathrm{ng} \mathrm{g}^{-1}$ ): $11.0 \pm 2.5,0.7 \pm 0.4,0.5 \pm 0.2$ $31 \pm 5.6, \quad 58 \pm 11.6$ and $103 \pm 11.6$ respectively (the scatter represents the standard deviation).

No definite trend is detected which could be linked to the Little Ice Age disturbance.
\end{abstract}

\section{INTRODUCTION}

Situated $1300 \mathrm{~km}$ inland at an elevation of $2850 \mathrm{~m}$ a.s.l., the South Pole is neither on the highest plateau nor at the most central location on the Antarctic continent. However, in addition to being the most important station for Antarctic atmospheric-chemistry research, the AmundsenScott base lies in a geographical area particularly well suited to glaciochemical studies (Legrand and Delmas 1984), due to a relatively stable snow-accumulation rate (Jouzel and others 1983, Mosley-Thompson and others 1985), sufficiently high to limit the smoothing of the seasonal variations in the various parameters recorded in the snow layers. On the East Antarctic plateau (such as Dome C or Vostok stations) the weakness of the accumulation rates is an advantage for long-term glaciochemical studies but a disadvantage for detailed studies covering a few centuries. At the South Pole, the 1000 year level can be reached relatively easily with the aid of drilling equipment. The detailed study of such a glaciochemical record, although time-consuming (analysis of several hundred samples is required for good time resolution), is not an impossible task.

In the context of a deep ice-core drilling program at the South Pole, the results which can be obtained from such an ice core are most valuable. They allow "calibration" of glaciochemical methods for a relatively well-known period, even if knowledge of the past environment is far less well documented for the Southern than for the Northern Hemisphere.

For the period under consideration, the only South Pole data available hitherto relate to microparticles, obtained by Mosley-Thompson and Thompson (1982) from a $101 \mathrm{~m}$ firn core drilled in 1974, and to nitrate concentrations, obtained by Parker and others (1982). Shorter sequences have been studied by Herron (1982), Boutron (1982) and Legrand and Delmas (1984) for other parameters of interest to atmospheric chemistry, whereas Giovinetto and Schwerdtfeger (1966), Jouzel and others (1983) and Stauffer and Schwander (1983) have investigated the accumulation rate, stable isotopes, and $\left(8^{18} \mathrm{O}\right)$ and $\mathrm{CO}_{2}$ concentrations respectively.

During the summer of 1983-84, several ice cores were drilled in the immediate vicinity of the Amundsen-Scott base. One of them (PS1, $130 \mathrm{~m}$ long) has been used for glaciochemical studies. This paper reports on the measurements made along this ice core, assumed to cover at least the last 1000 years. The purpose of this investigation was to assess the temporal variations in background atmospheric chemistry at the South Pole, assuming that snow chemistry is directly linked to the chemical composition of the aerosol. This assumption is a matter of serious discussion, particularly among atmospheric chemists. Since the developments exposed by Junge (1977), the debate has been reactivated time and time again, particularly by Davidson and others (1981) and by Barrie (1985). In fact, the chemistry of snow is not necessarily the same as that of the aerosol, but, for a given element or compound and at a given location, concentrations in the snow and in the air are most likely to vary in parallel. This assumption appears to be quite reasonable in terms of the study presented below and will not be discussed further in this paper.

What are the general features of the present-day chemistry of snow at the South Pole? Delmas and others (1982) and, later, Legrand and Delmas (1984) have demonstrated that the chemical composition of soluble impurities determined in South Pole precipitation is dominated by three gas-derived mineral acids $\left(\mathrm{H}_{2} \mathrm{SO}_{4}, \mathrm{HNO}_{3}\right.$ and $\mathrm{HCl}$ ). The other constituents are essentially the different components of sea salt (in particular $\mathrm{NaCl}$ ). The ion budget is small, generally less than $10 \mu \mathrm{Eq} \mathrm{I}^{-1}$, except during the 2 years following explosive volcanic eruptions of global significance (in which case the ion content can be as much as $\left.20 \mu \mathrm{Eq} \mathrm{1} ~^{-1}\right)$. The proton accounts for from one-third to nearly one-half of the total ion budget.

Neutralization of the acidity is very slight, as indicated by very low ammonium concentrations. Finally, insoluble impurities are almost negligible (less than $5 \%$ by weight of the total deposition).

Well-marked seasonal patterns have been detected for several of the ions (Herron 1982, Legrand and Delmas 1984). For instance, mineral-acid concentrations are at a maximum in summer, as are sea-salt compounds in autumn or winter.

Regarding the origin of these impurities (apart from sea salt), $\mathrm{H}_{2} \mathrm{SO}_{4}$ appears to be primarily marine-biogenic, $\mathrm{HNO}_{3}$ is derived from atmospheric nitrogen fixation by lightning, and $\mathrm{HCl}$ results from the interaction of $\mathrm{H}_{2} \mathrm{SO}_{4}$ with sea-salt particles. This very schematic description of the chemical composition of the snow at the South Pole will be developed in a more detailed manner in the discussion of our results.

\section{DATING THE PSI FIRN CORE}

The accurate dating of ice cores in areas of low accumulation rates $\left(<10 \mathrm{~g} \mathrm{~cm}^{-2} \mathrm{a}^{-1}\right)$ is a real problem, except when well-defined reference levels are available (as in Greenland). For the last 30 years, total beta radioactivity reference levels exist, allowing very accurate dating $( \pm 1$ year) of the snow layers (Jouzel and others 1983) Investigations of longer time series have demonstrated that the mean accumulation rate over several decades, as far as it can be evaluated, is relatively stable at the South Pole (Mosley-Thompson and Thompson 1982, Jouzel and others 1983, personal communication from A.J. Gow). Mean values are in the range $6.6-12.5 \mathrm{~g} \mathrm{~cm}^{-2} \mathrm{a}^{-1}$ (Jouzel and others 1983). 
More recently a double-conductivity spike has been clearly identified by electrical conductivity measurements (ECM) in five of seven South Pole firn cores (Legrand and others 1987). It has been attributed to two major volcanic eruptions in the Southern Hemisphere at the beginning of the ninteenth century (Tambora in 1815 and another eruption around the same time \pm 8 years). With the aid of these new reference levels, a mean accumulation of $6.5-9.3 \mathrm{~g} \mathrm{~cm}^{-2} \mathrm{a}^{-1}$ (depending on the firn core under consideration) has been calculated for the last 170 years. For the PS1 firn core, the signal of the Tambora eruption has been detected at $27.1 \mathrm{~m}$ depth, leading to a mean accumulation of $7.97 \mathrm{~g} \mathrm{~cm}^{-2} \mathrm{a}^{-1}$ from the surface up to the present time.

Microparticle measurements on a $101 \mathrm{~m}$ firn core (Mosley-Thompson and Thompson 1982) led to an estimated annual net accumulation equal to $7 \mathrm{~g} \mathrm{~cm}^{-2} \mathrm{a}^{-1}$ over nine centuries, whereas the stratigraphical study of a recent $202 \mathrm{~m}$ ice core (drilled $50 \mathrm{~m}$ from PS1) gives a mean accumulation of $8 \mathrm{~g} \mathrm{~cm}^{-2} \mathrm{a}^{-1}$ for the last $2000 \pm 60$ years (personal communication from A.J. Gow).

Taking into account the conductivity measurements on PS1 (Legrand and others, in press) and Gow's estimate for the $202 \mathrm{~m}$ ice core nearby, we have chosen the mean value of $8 \mathrm{~g} \mathrm{~cm}^{-2} \mathrm{a}^{-1}$ for dating the entire PS1 firn core. Using this value, the age of the bottom of the firn core is A.D. $1083 \quad{ }_{-150}^{+40}$ years, to allow for uncertainty about the accumulation rate in the range $6-10 \mathrm{~g} \mathrm{~cm}^{-2} \mathrm{a}^{-1}$ ).

\section{SAMPLE PREPARATION AND ANALYSIS}

Chemical measurements were made on 42 sections (40 cm long) selected every $2 \mathrm{~m}$ along the $130 \mathrm{~m}$ PS1 firn core. Each sample represents about $1.9-3.7$ years of precipitation (depending on depth) and the mean time interval between consecutive samples is about 24 years. In order to obtain chemical data representative of background conditions, samples at depth levels where ECM detected acid spikes (in particular the volcanic signals) were rejected.

Stringent precautions were taken in order to minimize contamination problems. All tools and containers which came into contact with the samples were first washed several times in double-deionized water and the sub-coring was done with mini-drilling equipment placed in a cold cleanroom according to a procedure described by Legrand and others (1984). After preparation, the samples were stored in a solid state at $-15^{\circ} \mathrm{C}$ in double-sealed polyethylene bags and were melted at room temperature just before analysis. The bags were pierced by the tip of the syringe used to inject the melt-water sample into the ion chromatograph. These additional precautions were taken, with respect to the methodology described by Legrand and others (1984), to improve the quality of the ammonium determinations.

All major soluble ions were determined by ion chromatography (on Dionex 2010i equipment), using two $3 \mathrm{ml}$ aliquots (the first for the cations, the second for the anions). Pre-concentration columns were used for both measurements.

Uncertainties and detection limits were calculated from the linear regression coefficients of the calibration curves, obtained with the aid of standard solutions.

\section{RESULTS AND DISCUSSION}

The results of the chemical measurements are summarized in Table I, In addition to the mean values (42 samples), we also give the variation range, $\sigma$ (the natural variability) and the precision of the measurements.

The composition reported in Table I, although incomplete (since $\mathrm{Ca}^{2+}, \mathrm{Mg}^{2+}$ and $\mathrm{H}^{+}$were not determined), confirms that at the South Pole the sea-salt components (indexed by $\mathrm{Na}$ ) are not dominant for the 1000 year time interval which was covered by this study. Gas-derived compounds (in particular, nitrates and sulfates) are the major constituents of the snow impurities. Non-sea-salt sulfate (excess sulfate, $\mathrm{SO}_{4}{ }^{*}$ ) has been calculated from total sulfate according to the relationship

$$
\mathrm{SO}_{4}^{*}=\mathrm{SO}_{4}-0.25 \mathrm{Na}
$$

Our results are generally in good agreement with the chemical data already available for South Pole snow over various periods, except for the ammonium values, which are nearly one order of magnitude lower than the values of Legrand and Delmas (1984) $\left(3 \mathrm{ng} \mathrm{g}^{-1}\right)$, which, in turn, are significantly lower than the values $\left(>10 \mathrm{ng} \mathrm{g}^{-1}\right)$ of Parker and Zeller (1979). As already emphasized in the section on the experiments, we have considerably improved the analytical protocol in order to minimize the influence of gaseous contaminants (in this case $\mathrm{NH}_{3}$ ) during laboratory

TABLE I. SUMMARY OF THE CHEMICAL RESULTS OBTAINED FROM THE MEASUREMENT OF 42 SAMPLES TAKEN ALONG THE $130 \mathrm{~m}$ PS1 FIRN CORE DRILLED AT THE SOUTH POLE.

For $\mathrm{NH}_{4}^{+}$and $\mathrm{K}^{+}$concentrations (very close to the detection limit of the method), the uncertainties are significantly higher than for other ions. $\mathrm{SO}_{4}{ }^{*}$ is excess sulfate (non-marine sulfate). The results of four data sets published by others are also given: (1) Boutron (1982), (2) Herron (1982), Parker and others (1982), (4) Legrand and Delmas (1984).

\begin{tabular}{|c|c|c|c|c|c|c|c|}
\hline Mean value & $\mathrm{Na}$ & $\mathrm{NH}_{4}$ & K & $\mathrm{Cl}$ & $\mathrm{NO}_{3}$ & $\mathrm{SO}_{4}$ & $\mathrm{SO}_{4}{ }^{*}$ \\
\hline $\begin{array}{l}\mathrm{ng} \mathrm{g}^{-1} \\
\mu \mathrm{Eq} 1^{-1}\end{array}$ & $\begin{array}{r}11.05 \\
0.48\end{array}$ & $\begin{array}{l}0.5 \\
0.03\end{array}$ & $\begin{array}{l}0.75 \\
0.02\end{array}$ & $\begin{array}{l}31 \\
0.88\end{array}$ & $\begin{array}{l}103 \\
1.67\end{array}$ & $\begin{array}{l}58 \\
1.20\end{array}$ & $\begin{array}{l}55.0 \\
1.15\end{array}$ \\
\hline $\begin{array}{l}\text { Variation range } \\
\left(\mathrm{ng} \mathrm{g}^{-1}\right)\end{array}$ & $4.4-15.5$ & $0.2-1.1$ & $0-2$ & $20-48$ & $84-134$ & $43-89$ & $40-86$ \\
\hline $\begin{array}{l}\text { Standard deviation } \\
\left(\mathrm{ng} \mathrm{g}^{-1}\right)\end{array}$ & 2.5 & 0.23 & 0.43 & 5.56 & 11.6 & 11.6 & 11.6 \\
\hline $\begin{array}{l}\text { Precision of } \\
\text { measurements }(1 \sigma) \\
\quad\left(\mathrm{ng} \mathrm{g}^{-1}\right) \quad \pm\end{array}$ & 1 & 0.5 & 0.4 & 4 & 4 & 9 & 9 \\
\hline $1928-77$ & 10.2 & - & 1.0 & - & - & - & - \\
\hline $1923-37$ & 15 & - & - & 30 & 75 & 45 & 41 \\
\hline last 12 centuries & 3) - & - & - & - & 100 & - & - \\
\hline $1959-69$ & 14.5 & 3.0 & 1.1 & 44.5 & 89 & 72 & 69 \\
\hline
\end{tabular}




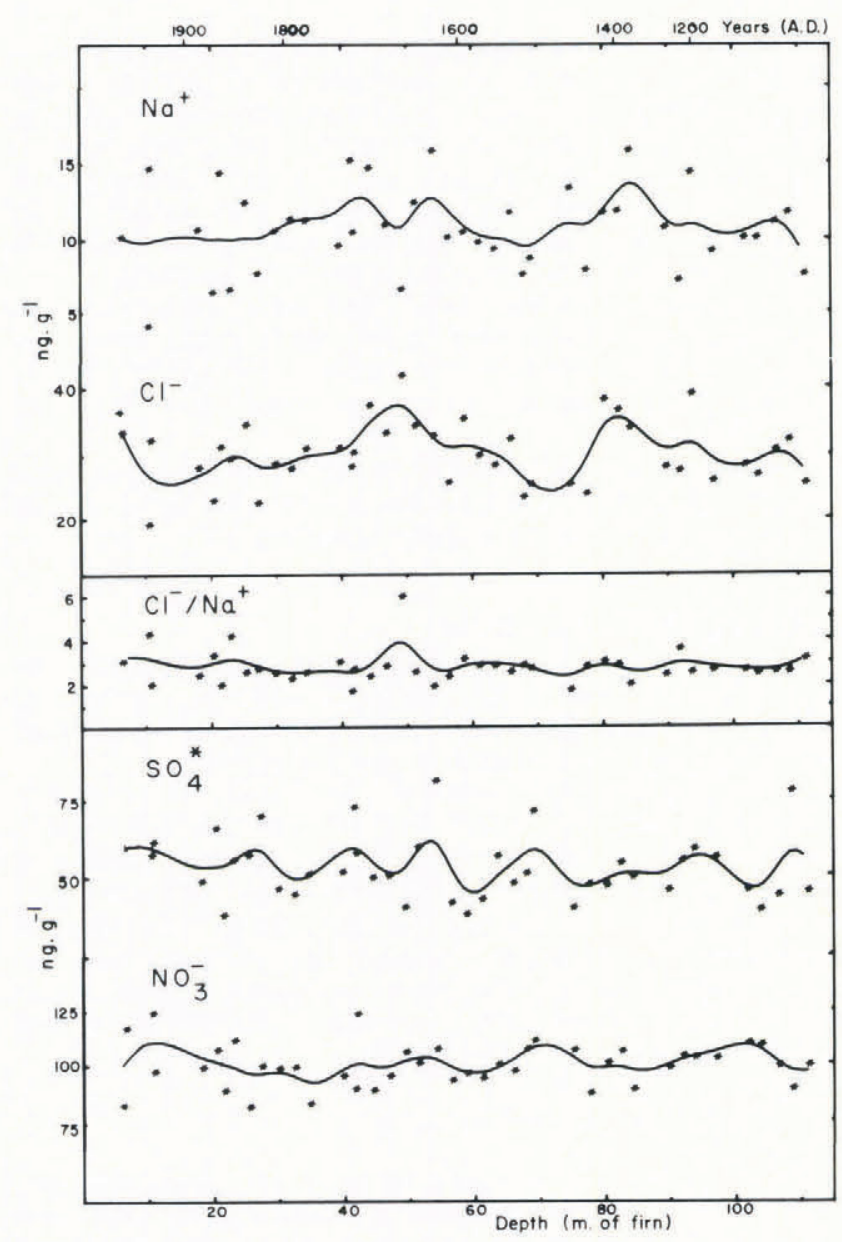

Fig.1. Sodium, chloride, excess sulfate and nitrate ion concentrations along the PS1 firn core. Solid lines were drawn by using a spline function where $\rho=0.1$.

work. Earlier $\mathrm{NH}_{4}$ measurements were erroneously high. The present values are most probably correct (Saigne and others, in press), allowing for the relatively high analytical uncertainties $( \pm 100 \%)$ at sub-ppb levels (Table I).

An obvious conclusion stemming from our observations is that the mean neutralization of the atmospheric acidity in this geographical area is of the order of $1 \%$, i.e. negligible.

We shall now focus the discussion on the time variations in the major ions $\mathrm{Na}, \mathrm{Cl}, \mathrm{SO}_{4}$ and $\mathrm{NO}_{3}$. The results obtained for the 42 depth levels have been plotted as a function of depth (Fig.1).

\section{Sodium and chloride}

Crustal sodium has been found to be very low in the aerosol collected at the Amundsen-Scott Station and therefore marine sodium is largely dominant ( $90 \%$; Cunningham and Zoller 1981). According to the same authors, $\mathrm{Cl}$ has a purely marine source. However, $\mathrm{Na}$ is better than $\mathrm{Cl}$ for indexing sea-salt deposition, due to the possible presence in the Antarctic atmosphere of $\mathrm{Cl}$ partly in gaseous form $(\mathrm{HCl})$, as shown indirectly by Maenhaut and others (1979) and Cunningham and Zoller (1981) from air measurements, and by Legrand and Delmas (1984 and in press) in snow. Therefore $\mathrm{Na}$ (rather than $\mathrm{Cl}$ ) concentration changes may be used to reconstruct the past variations in sea-salt deposition at the South Pole. Such variations could be linked to changes in the production, transport and deposition of marine aerosol particles. The strong seasonal pattern (with maxima in winter) found for $\mathrm{Na}$ at the South Pole (Cunningham and Zoller 1981, Legrand and Delmas 1984) is related partly to the frequency of storms in the sub-Antarctic ocean and partly to their degree of penetration over the Antarctic continent. For long-term variations, changes in the snow-deposition rates may be relevant.
The $\mathrm{Na}$ (as well as $\mathrm{Cl}$ ) depth profiles obtained from our measurements exhibit no definite trend over time, the values varying in the range $4.4-1.15 \mathrm{ng} \mathrm{g}^{-1}$ (and $20-48 \mathrm{ng} \mathrm{g}^{-1}$ for $\mathrm{Cl}$ ). This suggests no major long-term changes in the three causes of variability listed above.

Additional information of environmental concern could be drawn from the variations in the $\mathrm{Cl} / \mathrm{Na}$ ratio $(\mathrm{R})$, which at several Antarctic locations has been found to be significantly different from its reference value (1.8) in bulk sea-water (Legrand and Delmas 1984, Palais and Legrand 1985, Legrand and Delmas, in press). For the South Pole itself, the measurements indicate that on average the aerosol sea-salt particles are $\mathrm{Cl}$-depleted (Cunningham and Zoller 1981), whereas the sea salt deposited with the snow is Cl-enriched (Legrand and Delmas 1984). This shows that the snow measurements include a certain amount of $\mathrm{HCl}$ not taken into account by aerosol sampling. Consequently the $\mathrm{Cl} / \mathrm{Na}$ ratios determined in the snow may be either higher (the general case at the South Pole in recent decades) or lower than 1.8 , according to the amount of $\mathrm{HCl}$ deposited together with the fractionated sea-salt aerosol.

The chemical cause of this fractionation is most probably the reaction of $\mathrm{H}_{2} \mathrm{SO}_{4}$ aerosol droplets with the sea-salt particles. This reaction has been proposed for temperate latitudes (Eriksson 1960, Yue and others 1976, Kritz and Rancher 1980, Clegg and Brimblecombe 1985) as well as for Antarctic latitudes (Legrand and Delmas, in press).

How does $R$ vary over the last millennium? Has it always been higher than 1.8 or did it reach values lower than 1.8 in the past? The variation range reported in Figure 1 is $2-6$ and shows no definite trend over time. This relative stability of $R$ is an indication that no radical change in the behaviour of the regional atmosphere around the South Pole occurred over the last millennium, at least with respect to this sea-salt fractionation. This is not the case, for instance, in the Dome C area, where a 220 year profile (Legrand and Delmas, in press) has shown that $R$ changed radically between the nineteenth and the twentieth centuries, passing from values lower than 1.8 to values higher than 1.8. This could be an indication that what occurs in West Antarctica (the source of air masses crossing over the South Pole) may not necessarily be similar to what occurs over the East Antarctic plateau (where Dome C is located). It is worth noting that no fractionation at all has been observed for the sea salt in snow at Byrd Station, a West Antarctic site located at a lower elevation and with a more maritime weather regime than the South Pole.

\section{Sulfate}

In South Pole precipitation, excess sulfate generally represents more than $90 \%$ of the total sulfate. Its origin is probably essentially marine-biogenic, as proposed and discussed elsewhere (Delmas 1982, Legrand and Delmas, in preparation), except after large volcanic events of global significance, which may affect the Antarctic troposphere by the transport of volcanic sulfur (as $\mathrm{H}_{2} \mathrm{SO}_{4}$ ) through the stratosphere. As we have selected here firn sections in which the volcanic influence is assumed to be minor, the sulfate depth profile reported in Figure 1 is assumed to represent the input of marine-biogenic sulfate to the Antarctic continent. The variations observed are linked either to transport phenomena, or to changes in the marine-biogenic activity of the sulfur-production areas (assumed to be essentially the sub-Antarctic ocean) Variations in snow-accumulation rates may also be responsible for changes in concentration (Legrand 1985). The variability of excess sulfate is not linked to that of sodium, probably because these componds are not carried by the same kind of aerosol (even though they originate in the same geographical areas).

The general trend of the sulfate profile reported in Figure 1 demonstrates that no major long-term change has occurred in the deposition of this compound at the South Pole. A similar conclusion can be drawn for Dome $\mathrm{C}$ over the last 220 years (Legrand 1985), despite a significant change in the neutralization of $\mathrm{H}_{2} \mathrm{SO}_{4}$ by sea salt in the snow at this site.

\section{Nitrate}

The origin of nitrate found in Antarctic snow is 
unclear. From the examination of numerous new data sets, Legrand and Delmas (1986) have proposed $\mathrm{N}$-fixation by lightning at mid-latitudes and subsequent long-range transport to high latitudes as the most likely source of Antarctic nitrate. Snow measurements have also demonstrated that $\mathrm{NO}_{3}$ ions are present over the ice cap as gaseous $\mathrm{HNO}_{3}$. The South Pole is the Antarctic location which exhibits the highest nitrate concentrations in snow: $1.67 \mu \mathrm{Eq} 1^{-1}$, whereas $0.50-0.7 \mu \mathrm{Eq} \mathrm{1}^{-1}, 0.2-0.4 \mu \mathrm{Eq} \mathrm{1}^{-1}$ and $0.6-0.8 \mu \mathrm{Eq}^{-1}$ have been found for similar periods at D57 (Terre Adélie), Dome C (East Antarctic high plateau) and Byrd Station (West Antarctica) respectively. We have no satisfactory explanation, but this spatial variability, if not linked to pure deposition phenomena, could be an indication of a relatively short life span for $\mathrm{HNO}_{3}$ in the Antarctic atmosphere (of the order of a few days - a rather controversial assertion) and the injection of $\mathrm{HNO}_{3}$ from the upper to the lower tropospheric layers over the South Pole, i.e. at the center of the Antarctic vortex.

Finally, the sampling was unsuitable for detecting sudden $\mathrm{NO}_{3}{ }^{-}$increases (spikes lasting 1 or 2 years) like those found at D57 (Zanolini and others 1985).

\section{The Little Ice Age and the chemical record - conclusion}

Climatic changes can modify atmospheric circulation patterns and the strength of the aerosol sources. The consequences of such environmental changes are clearly recorded in deep ice cores encompassing the last glacial age. The Little Ice Age is a minor climatic change which affected mainly the Northern Hemisphere from the sixteenth to the nineteenth centuries. Thompson and others (1986) found evidence of this event in the ${ }^{18} \mathrm{O}$, microparticle and conductivity profiles of the tropical Quelccaya ice cap in Peru between about A.D. 1600 and about A.D. 1900. The $\delta^{18} \mathrm{O}$ results at the South Pole (Jouzel unpublished) indicate no major changes over the last millennium. Our chemical depth profiles are also negative with respect to a possible record of the Little Ice Age (this period corresponds to depths of $72-14 \mathrm{~m}$ ). In Antarctic ice, ice ages are marked by considerable increases in the sea-salt and crustal-dust inputs (see, for instance, Petit and others 1981 or Legrand 1985). This observation suggests that an increase in the sea-salt deposition could also be expected at the South Pole for the period of the Little Ice Age. No such definite fluctuation in the natural variability of the $\mathrm{Na}$ and $\mathrm{Cl}$ values, except possibly a soft "bump" from 1600 to 1700 , is visible in Figure 1. With stronger winds, the $\mathrm{Cl} / \mathrm{Na}$ ratio would be nearer to its reference level of 1.8 (Legrand and Delmas, in press), but our $\mathrm{Cl} / \mathrm{Na}$ profile does not exhibit such a trend for these years. Finally, the concentrations of the acid anions $\left(\mathrm{NO}_{3}\right.$, excess $\mathrm{SO}_{4}$ and excess $\left.\mathrm{Cl}\right)$ are neither exceptionally high nor exceptionally low over this period.

From our measurements we therefore conclude that the environmental impact of the Little Ice Age, if any, was negligible at the South Pole.

On the other hand, this new data provides clear evidence of the stability of atmospheric environmental conditions in this area of the Antarctic over the last millennium, a conclusion which is not necessarily applicable to the entire continent.

These data also provide an assessment of the natural variability of the major chemical parameters measured along deep ice cores, a factor which should be taken into account in the interpretation of long-term glaciochemical profiles.

\section{ACKNOWLEDGEMENTS}

We thank $J$ R Petit and $M$ Legrand for their participation in the field work and for helpful discussions, and $\mathbf{J}$ Jouzel and $A$ J Gow for making available their unpublished data. Financial support was provided by the CNRS (Programme Interdisciplinaire sur l'Environnement), T.A.A.F. (Terres Australes et Antarctiques Françaises) and the U.S. National Science Foundation (Division of Polar Programs).

\section{REFERENCES}

Barrie L A 1985 Atmospheric particles: their physical and chemical characteristics, and deposition processes relevant to the chemical composition of glaciers. Annals of
Glaciology 7: 100-108

Boutron C F 1982 Atmospheric trace metals in the snow layers deposited at the South Pole from 1928 to 1977. Atmospheric Environment 16(10): 2451-2459

Clegg S L, Brimblecombe P 1985 Potential degassing of hydrogen chloride from acidified sodium chloride droplets. Atmospheric Environment 19: 465-470

Cunningham W C, Zoller W H 1981 The chemical composition of remote area aerosols. Journal of Aerosol Science 12: 367-384

Davidson C I, Chu L, Grimm T C, Nasta M A, Qamoos M P 1981 Wet and dry deposition of trace elements onto the Greenland ice sheet. Atmospheric Environment 15: 1429-1437

Delmas R J 1982 Antarctic sulphate budget. Nature 299(5885): 677-678

Delmas R J, Briat M, Legrand M 1982 Chemistry of south polar snow. Journal of Geophysical Research 87(C6): 4314-4318

Eriksson E 1960 The yearly circulation of chloride and sulfur in nature: meteorological, geochemical and pedological implications. Part II. Tellus 12(1): 63-109

Giovinetto M B, Schwerdtfeger W 1966 Analysis of a 200 year snow accumulation series from the South Pole. Archiv für Meteorologie, Geophysik und Bioklimatologie Ser A 15(2): $227-250$

Herron M M 1982 Glaciochemical dating techniques. American Chemical Society Symposium Series 176: 303-318

Jouzel J, Merlivat L, Petit J R, Lorius C 1983 Climatic information over the last century deduced from a detailed isotopic record in the South Pole snow. Journal of Geophysical Research 88(C4): 2693-2703

Junge C E 1977 Processes responsible for the trace content in precipitation. International Association of Hydrological Sciences Publication 118 (General Assembly of Grenoble 1975 - Isotopes and Impurities in Snow and Ice): 63-77

Kritz M A, Rancher J 1980 Circulation of $\mathrm{Na}, \mathrm{Cl}$ and $\mathrm{Br}$ in the tropical marine atmosphere. Journal of Geophysical Research 85(C3): 1633-1639

Legrand M 1985 Chimie des neiges et glaces antarctiques: un reflet de l'environnement. Grenoble. Laboratoire de Glaciologie, Université Scientifique et Médicale de Grenoble (Publication 478)

Legrand M R, Delmas R J 1984 The ionic balance of Antarctic snow: a 10-year detailed record. Atmospheric Environment 18(9): 1867-1874

Legrand M R, Delmas R J 1986 Relative contributions of tropospheric and stratospheric sources to nitrate in Antarctic snow. Tellus 38B(3-4): 236-249

Legrand $\mathrm{M}$, Delmas $\mathrm{R} \mathbf{J}$ In press Formation of $\mathrm{HCl}$ in the Antarctic atmosphere. Journal of Geophysical Research:

Legrand M, De Angelis M, Delmas R J 1984 Ion chromatographic determination of common ions at ultratrace levels in Antarctic snow and ice. Analytica Chimica Acta 156: 181-192

Legrand M R, Petit J R, Korotkevich Ye S 1987 DC conductivity of Antarctic ice in relation to its chemistry. Journal de Physique 48(C1): 605-611

Maenhaut W, Zoller W H, Duce R A, Hoffman G L 1979 Concentration and size distribution of particulate trace elements in the south polar atmosphere. Journal of Geophysical Research 84(C5): 2421-2431

Mosley-Thompson E, Thompson L G 1982 Nine centuries of microparticle deposition at the South Pole. Quaternary Research 17(1): 1-13

Mosley-Thompson E, Kruss P D, Thompson L G, Pourchet M, Grootes P 1985 Snow stratigraphic record at South Pole: potential for paleoclimatic reconstruction. Annals of Glaciology 7: 26-33

Palais J M, Legrand M 1985 Soluble impurities in the Byrd Station ice core, Antarctica: their origin and sources. Journal of Geophysical Research 90(C1): 1143-1154

Parker B C, Zeller E J 1979 Nitrogenous chemical composition of Antarctic ice and snow. Antarctic Journal of the United States 14(5): 80-82

Parker B C, Zeller E J, Gow A J 1982 Nitrate fluctuations in Antarctic snow and firn: potential sources and mechanisms of formation. Annals of Glaciology 3: 243-248

Petit J R, Briat M, Royer A 1981 Ice age aerosol content 
from East Antarctic ice core samples and past wind strength. Nature 293(5831): 391-394

Stauffer B, Schwander J 1983 Core processing and analyses of ice cores drilled at the South Pole. Antarctic Journal of the United States 18(5): 114-116

Thompson L G, Mosley-Thompson E, Dansgaard W, Grootes P M 1986 The Little Ice Age as recorded in the stratigraphy of the tropical Quelccaya ice cap. Science 234(4774): 361-364

Yue G K, Mohnen V A, Kiang C S 1976 A mechanism for hydrochloric acid production in cloud water. Air and Soil Pollution 6: 277-294

Zanolini F, Delmas R J, Legrand M 1985 Sulphuric and nitric acid concentrations and spikes along a $200 \mathrm{~m}$ deep ice core at D 57 (Terre Adélie, Antarctica). Annals of Glaciology 7: 70-75 